Vol. XXIII No $1 \quad 2017$

\title{
MODERN APPROACHES IN THE TRAINING OF MILITARY POLICE CADETS AT VASSIL LEVSKI NATIONAL MILITARY UNIVERSITY
}

\author{
Krastyu KRASTEV \\ "Vasil Lesvski” National Military University, Veliko Tarnovo, Bulgaria \\ krustev_kr@abv.bg
}

\begin{abstract}
The mission of the Vasil Levski National Military University is to build its students morally, mentally and physically, to indoctrinate them with the ideals of patriotism, duty and honour, to form them as individuals and leaders. The graduated students have to possess leadership qualities, be able to develop and apply scientific knowledge, manage public and special structures in peacetime and crises and to participate in national and multinational projects aiming at maintaining security, peace and development of society. The present paper describes some results of the implementation of the modern person centered educational approaches to training of the Military police cadets.
\end{abstract}

\section{Keywords: training approaches, cadets, military police}

\section{Introduction}

The mission of the Vasil Levski National Military University is to build their students morally, mentally and physically, to indoctrinate them with the ideals of patriotism, duty and honor, to form them as individuals and leaders, possessing leadership qualities, able to develop and apply scientific knowledge, manage public and special structures in peacetime and crises and to participate in national and multinational projects aiming at maintaining security, peace and development of society.

The mission of Specialized Training Department is to spread professional knowledge and training to quality level in the Security and Defence Field of higher education, combined with a fundamental understanding of the basic principles, methods and management tools, to create opportunities for learners to their realization in the Bulgarian army, civil service and local government.

The activity of the department is in agreement with the European and national trends in modern education. The focus of this paper is the training of cadets at NMU for the needs of Military Police.

The object of the report is the personalityoriented type of educational technology.

The main hypothesis that the author raises is that when using and implementing person-centered type of educational technology, the efficiency of the educational process of cadets MPs will increase and consequently their GPA by quantitative and qualitative indicators will increase, too.

2. Characteristics of the military education process at Vasil Levski National Military University

\subsection{Main objectives}

The main objectives of the military educational process are identified and defined in the regulatory framework of Vasil Levski NMU.

They are as follows - preparation and conducting of a highly effective educational process based on modern approaches and methods of training; integration in the 
curricula and lecture fund of adopted standards for achieving a high level of interoperability; study of combat experience from the participation of units of the Bulgarian Army in missions abroad and timely integration of lessons learned in the educational process; improvement of existing educational facilities for conducting quality education in the new range of tasks in operations other than war and post-conflict interoperability; maintaining constant contact with the users of staff educated in the direction of meeting current needs, and improving and upgrading their professional qualifications; establishing and maintaining professional contacts with military training structures of NATO member countries and partners from the Partnership for Peace Initiative.

Of course, the above objectives cannot be determined as exhaustive, but rather as guidance in the design of the courses focused on their implementation and achievement.

\subsection{Main tasks}

The Rules and Regulations of Vasil Levski National Military University define the main tasks in the cadet training.

They are as follows -conducting effective educational process incorporating traditional and contemporary topics; timely upgrade of the lecture fund; development of new curricula and introducing new subjects in the military training of cadets; improving the existing and creating new educational facilities; integration of modern forms and methods of training in the specialized military training; use of interactive training systems for combat training in field exercises and camps; providing opportunities for additional professional qualifications of the faculty and cadet staff in courses organized by the Specialized Training Department.

\section{Expected learning outcomes of Military Police cadets}

As a result of this training program, the trainees should acquire new knowledge about - the structure, functions and tasks of the Military Police as a structure of the Armed Forces maintaining the order and security in the Ministry of Defence, in the structures directly subordinated to the Minister of Defence, and in the Bulgarian Army at whole; organization, armaments, military equipment, dislocation and perceptions of conducting combat operations by the formations of the Armed Forces of the Republic of Bulgaria; the main tasks of the Military Police, associated with the detection, prevention, interception and investigation of crimes and other offenses that threaten the order and security, through control and security activities; the main tasks of the Military Police related to the detection and neutralization of terrorist actions against the armed forces, agents and forces of NATO and countries participating in military exercises on the territory of the Republic of Bulgaria and abroad; military police support operations to complete tasks of the main types of missions of $\mathrm{BA}$; procedures in the work of commanders of military police formations to guarantee military order and discipline in garrisons and military units and security of military objects; operational and tactical aspects of the Balkan theater of war and the nature of their fortification equipment.

As a result of the training, the future young officers need to build new capabilities - to implement in full the required by their functional duties analytical, prognostic and information activities; to fully organize and firmly manage the actions of their entrusted military police formation in the performance of their daily routine operations; to assist the commanders in the entire range of operation by organizing and supporting the movement of troops, regulation and control of traffic on the main roads of communication, events to guard the area, patrolling and securing the safety of individuals, performing all kinds of detentions of military people and civilians; to lead the process of collecting, analyzing 
and reporting operational information, law enforcement, prevention, detection and investigation of crime, collection and exchange of information; to apply in their practice as Military Police employees the documents regulating their activity; to apply specific tactics and maneuvers typical of the Military Police staff in the conduct of operational and investigative activities; to plan and organize the actions of their entrusted their military police formation in participating in expeditionary operations.

Value orientations and attitudes are loyalty to the institution they belong to; tolerance, openness and respect for different views and ideas; personal responsibility and respect for fundamental freedoms and human rights; interpersonal, social and civic competences; aesthetic, moral and health culture; readiness and desire for lifelong learning; communication skills; team work in heterogeneous environments; caring for others, building a spirit of trust, motivation and responsibility for tasks; ethics of communication in the military hierarchy; adherence to the ideals of patriotism, duty and honor.

\section{Introducing a person-centered type of technology in teaching cadet MPs}

The analysis of the modern pedagogical theories and the use of interactive teaching methods provide an opportunity to integrate Hutorskoy's theory that represents the personality-oriented type of technology through the creation of individual educational trajectory under the guidance of the teacher. Personality-oriented education of cadets aims at providing the following rights and opportunities - freedom of choice and expression of individual meaning and purpose in each training course, topic and class; the right to personal interpretation and understanding of fundamental concepts and categories; the right to development of individual educational programs on the studied course for the semester or for the academic year; the right to select individual pace of learning, forms and methods to solve educational tasks, quality control, reflection and self-assessment of their activities on the basis of knowledge of their individual circumstances; individual selection of subjects studied, creative laboratories and those types of classes in them that are consistent with the underlying curricula as subjects and classes of your choice; enhancing and deepening the content of the training course; individual choice of additional topics and creative activity by subjects; the right of an individual picture of the world and individual sound positioning in any educational field.

The following can be determined as basic elements of individual educational activities of the cadets - the meaning of the activity; the setting of personal goals; the action plan; completion of the plan; reflection /understanding of own activity/; evaluation; correction and redefining of the objectives.

It is always important to motivate the upcoming activity - it increases the attention of cadets, activates them and stimulates the expected beneficial activity. When motivation is tied to personal goals of cadets, that the teacher should be well aware of, it is easier to plan activities and to realize them in an appropriate way according to the level of the training and development of the students at the time.

The including of reflection and evaluation / self-evaluation, to be exact / further contributes to increasing the efficiency of operations and creating conditions for selfimprovement and development of students.

The element provided for a possible correction and redefinition of the objectives is necessary in cases of error or reaching a new stage in the development of the cadet personality.

It is obvious that cadets themselves are also included in person-oriented technologies in goal setting, planning, preparation, implementation and reflection of the military pedagogical process.

For the purpose of this study, an analysis of interdisciplinary connections between 
subjects in the curriculum of the MP cadets has been made, where as a key determinant we have the knowledge $\mathrm{K}$, which should be acquired in the training process.
Table 1 lists the subjects and the designation of the respective determinants.

\begin{tabular}{|c|l|l|}
\hline \multicolumn{2}{|c|}{ Codes } & \multicolumn{1}{|c|}{ Subjects 1 Knowledge relations between the subjects } \\
\hline K1 & English Language & Knowledge Relations - K \\
\hline K2 & Military Vehicles Engineering & K2-K8-K-K11-K12 \\
\hline K3 & Balkan Language & K3-K4-K13-K16 \\
\hline K4 & Military History & K4-K5-K14-K16 \\
\hline K5 & Ethnic, religious and spiritual aspects of security & K5-K12-K14-K16 \\
\hline K6 & $\begin{array}{l}\text { Communication and Information Systems in } \\
\text { Security Management }\end{array}$ & K6-K1-K11-K16 \\
\hline K7 & Leadership Training & K7-K1-K8-K11 \\
\hline K8 & Shooting Training Methods & K8-K9-K-17-K18 \\
\hline K9 & Firearms Training Methods & K9-K8-K11-K15 \\
\hline K10 & Drill Methods & K10-K7-K15-K18 \\
\hline K11 & Special Tactics Methods & K12-K4-K8-K18 13 \\
\hline K12 & European Union Law & K13-K4-K12-K15 \\
\hline K13 & Regional and national infrastructure and security & K14-K4-K5-K13 \\
\hline K14 & Social political history of Bulgaria & K15-K7-K9-K11 \\
\hline K15 & Military Units Service & K16-K5-K13-K15 \\
\hline K16 & $\begin{array}{l}\text { Structure and functions of the security services in } \\
\text { the state and local administration }\end{array}$ & K17-K8-K9-K11 \\
\hline K17 & Theory of shooting and firearms training & K18-K7-K11-K15 \\
\hline K18 & Special Tactical Training & \\
\hline & & \\
\hline
\end{tabular}

The analysis of the relationships of knowledge acquired in the respective subjects reveals the interdependencies among them.

The ways to achieve the objectives and complete the tasks of the person-oriented training can be as follows:

- the cadets individual tasks receive on each topic;

- organization of group academic work;

- formulating creative tasks that involve individual performance by each cadet;

- cadets' initiative to draw up lesson plans for themselves, choose the content of their homework assignment for creative activity, individual training schedule on the subject for a certain period of time.
This inevitably raises the question: "How to simultaneously train all cadets differently?"

Experts outline two opposite routes, each containing an individual approach:

- The first method - differentiation of training, according to which each cadet is approached individually, differentiating the learning material in terms of complexity, focus and other parameters.

- The second method - suggests that own way education is created for each cadet in each of the studied educational fields.

Every cadet is given the opportunity to create their own educational trajectory to learn the different academic subjects. (See Fig.1) 


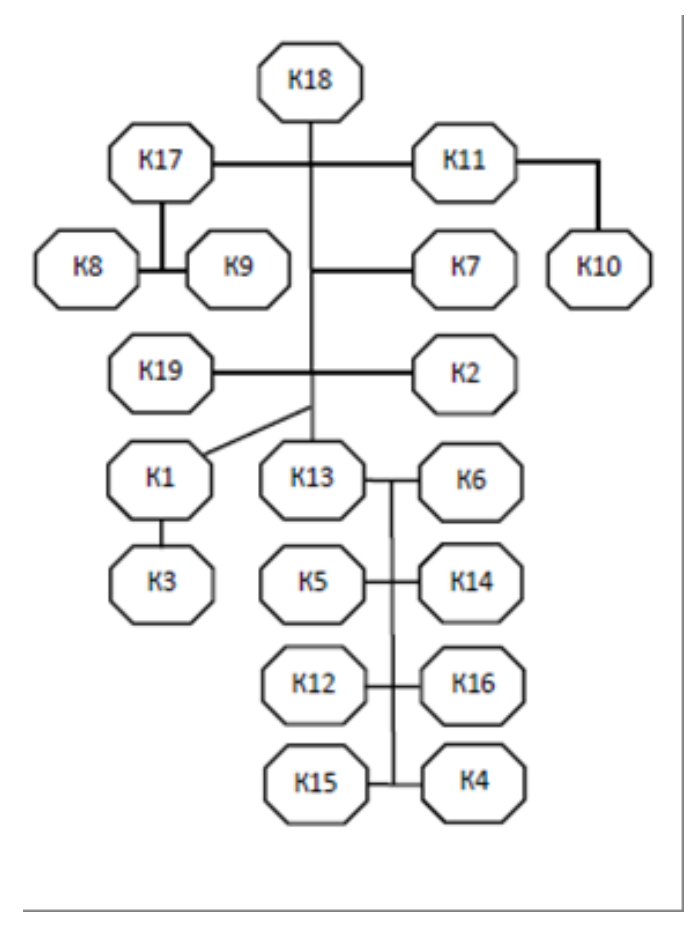

Figure 1: Individual educational trajectory (variant)

It is necessary to emphasize that the task of education is to provide individual area of creative development for each cadet and the technology for the realization of individual trajectory includes 7 stages: Stage 1 . Diagnosis of cadets individual characteristics. Stage 2: Defining the fundamental educational subjects. Stage 3: Building a specific personal attitude in the cadets to the objects of the study. Stage 4. Programming by each cadet of individual educational activities. Stage 5. Simultaneous realization of the individual educational programs of the cadets. Stage 6 . Demonstration of their educational products. Stage 7. Reflection and evaluation of the activities. [1]

These stages are acceptable; the sequence is logical; there is a natural correlation and sequence among them. [2,3] Each has its place and importance. There is clearly seen relevance to the fundamental elements of the mentioned individual educational activities of the cadets.

\section{Model for integrating individual educational trajectories}

The model for integrating individual educational trajectory in the training of MP cadets for one semester includes several components - organizational, theoretical, practical, control and evaluation, and optimization as shown in Figure 2. The organizational component includes setting goals of the cadet under the direction of a lecturer from the department and making an individual plan; preparation of individual educational trajectory in accordance with the proposed individual plan of each cadet, given the self-assessment of personal abilities and opportunities for training; approval of the individual educational trajectory by the head of the department.

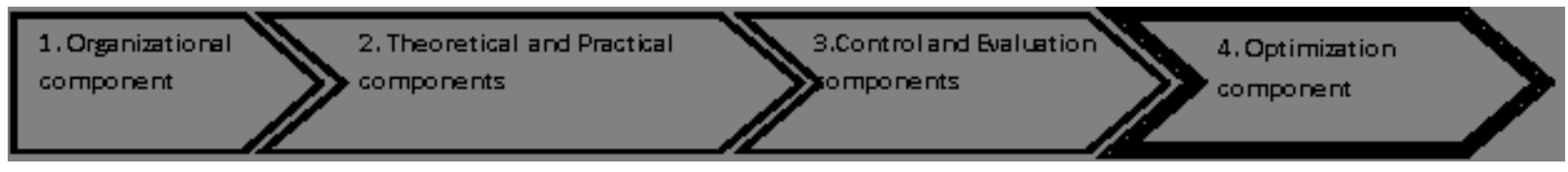

Figure 2: Components of the model for integrating individual educational trajectory for one semester 
The theoretical and practical component covers on one hand the period specified by the cadet for acquisition and mastering of theoretical knowledge on the subject and, on the other, the set of practical actions, training, conducting practical experiments and other activities related to the acquisition and improvement of practical skills of the cadets.

The control and evaluation component comprises evaluation tools with which to measure the performance of the trainees in the respective subjects in accordance with the scheduled curricular methods - tests, project assignments, examination tests, etc. The optimization component is an integral component allowing the upgrade of knowledge and skills of cadets at their desire and judgment. The opportunity for this upgrade of professional knowledge and skills is integrated in the optimization component, which defines it as a field for manifestation of the reflexive function of the pedagogical process.

In the proposed model (Figure 3 ) individual educational trajectories in civil and military specialty for all semesters have been integrated; as the periods for individual reflection in both areas of knowledge clearly stand out. In order to realize the opportunities for individual reflection, it is necessary to encourage the cadets to improve their performance in the previous semester of individual educational trajectories.

Reflection is socio-culturally conditioned, instrumental intellectual procedure / process, a set of conscious and controlled mental actions / targeted and meaningful to self-knowledge: knowledge of their own cognitive activity and own personality [4]

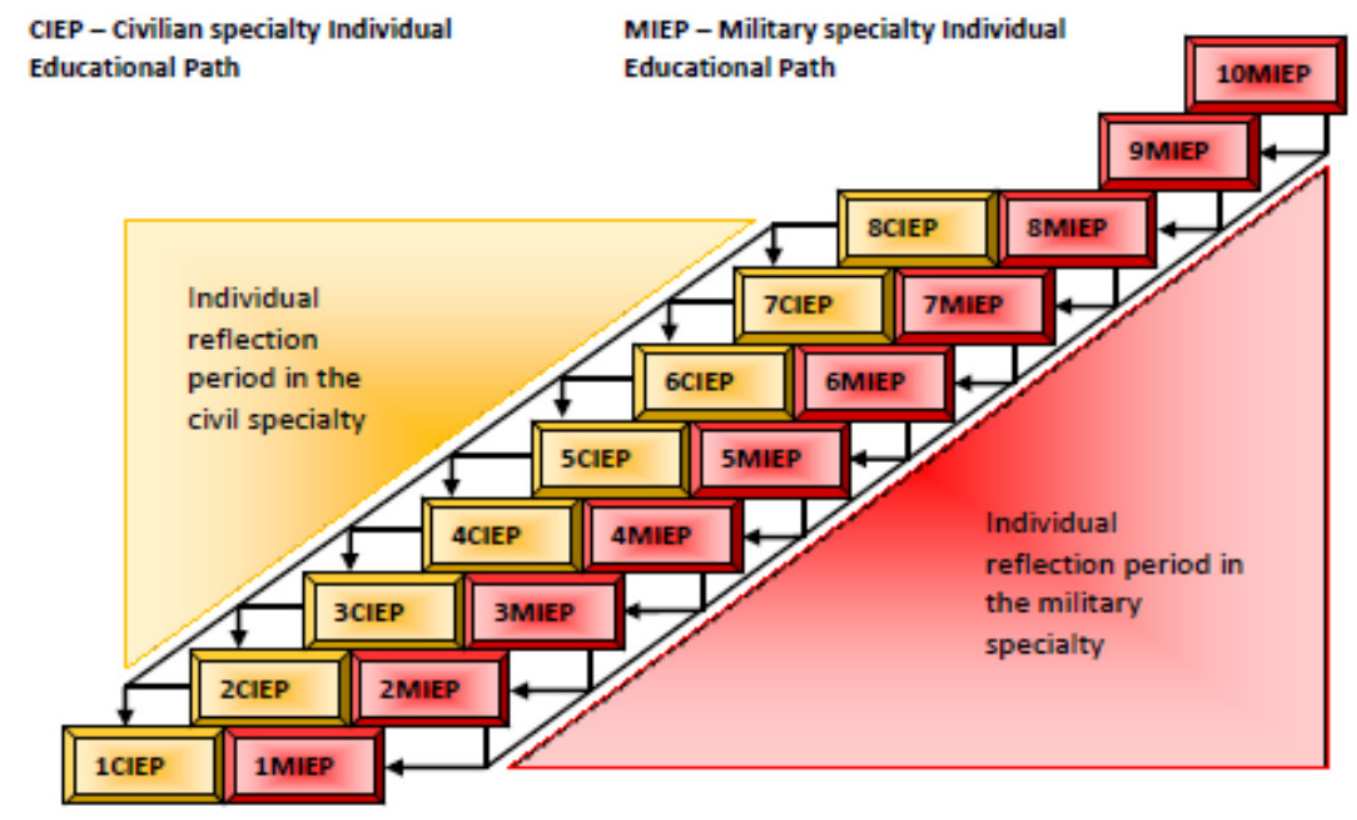

Figure 3: Model for individual educational technology integration

Contemporary professionals recognize the need to build a common theoretical and applied model in which and through which to systematize abstract theoretical ideas for reflection, to transform into practical midrange theories, and on this basis to develop a system of methodological developments and reflexive tools where ideas of reflection can be brought down to applied technology. $[5,6,7,8]$

It is crucial for the fate of reflexive problem itself that it does not remain only in the form of an abstract theory or choice of theoretical postulates that almost defy verification, forgery, i.e. they can hardly be empirically verified. The main ideas in the 
reflection should be able to formulate whose logical consequences that can be traced and verified empirically, to prove or disprove $[9,10,11]$

To achieve innovative intentions it is needed to provide the right environment for self-education of MP cadets in order to stimulate the achieving of the desired outcome for an optimal period of time.

\section{Conclusion}

Finally, it should be noted that results from the use of modern individual approaches to the training of MP cadets should be subject to a more in-depth analysis and measurement with the appropriate scientific tools. The expected increased effectiveness of their training should occur in quantitative and qualitative terms, which will be the subject of a further research.

\section{References}

[1] Vasilev D., Y. Merdzanova. Theory and methods of professional orientation. Sofia, UP „St. Kliment Ohridski”, 2003, p.92.

[2] Gyurova V. \& all, Provocation training process, Sofia, Askoni Publisher, 1997, p.73.

[3] Ilieva M., S. Terzieva. Self-evaluation and self-identification - Strategies in educational and scientific policy, Vol. 3., pp.34-42, 2001.

[4] Nikov A., Pedagogical psychology, Sofia, Karl Marx Publ., 1989, p.127.

[5] Rasheva-Merdzanova Y. Professional pedagogy in tradition and perspective, Sofia, UP „St. Kliment Ohridski”, 2004, p.172.

[6] Terzieva S. Modern educational strategies, Sofia Publ., 2003, p.46.

[7] Petrov P., Atanasova M.. Educational technologies and learning strategies, Sofia Publ., 2001, p.42.

[8] Marquardt, M., Leonard, H. S., Freedman, A., \& Hill, C.: Action learning for developing leaders and organizations: Principles, strategies, and cases. Washington, DC: APA 2009.

[9] Chiu, M. M.: Adapting teacher interventions to student needs during cooperative learning, American Educational Research Journal, 41, pp.365-399, 2004.

[10] Coffield, F, Moseley, D., Hall, E., Ecclestone K.: Learning styles and pedagogy in postearning: A systematic \& critical review, Learning \& Skills Research Centre London, 2004, p.214.

[11] Moon, J.: A Handbook of Reflective and Experiential Learning: Theory and Practice, London: Routledge Falmer, 2004, p. 126. 